\title{
Anthropometric Parameters and Adiposity of Term Egyptian Neonates
}

\author{
Mohamed S. El shimi, Rania M. Abdou, Ramallah AbdelAziz
}

Pediatrics and Neonatology Department, Faculty of Medicine, Ain Shams University, Cairo Egypt.

Received: April, $2018 \quad$ Accepted: June, 2018

\begin{abstract}
Background: The heterogeneity of the neonatal anthropometric measurements amongst different population groups can be quite striking. Objective: to formulate anthropometric percentile values for Egyptian full term newborns ( $\geq 37$ weeks), and to compare these values with the currently international charts. Method: We obtained the birth weight, length; head circumference and skin fold thickness of 6780 full term newborns from three different hospitals in Egypt which represent different socioeconomic standard. Results: the mean birth weight, length, head circumference and skin fold thickness of full term male neonates were $3.23 \mathrm{~kg}, 50.28 \mathrm{~cm}, 34.95 \mathrm{~cm}$ and $4.22 \mathrm{~mm}$ respectively, and for full term female neonates were $3.06 \mathrm{~kg}, 49.2 \mathrm{~cm}, 34.19 \mathrm{~cm}$ and $3.95 \mathrm{~mm}$ respectively. As such, full term male newborns were heavier, taller, with larger head circumference and bigger skin fold thickness than full term female newborns and these findings differ from the values obtained from the currently used percentile charts of Lubchenco which underestimate the birth weight, height and head circumference at the $10^{\text {th }}, 50^{\text {th }}$ and $90^{\text {th }}$ percentile levels. Conclusion: It is safe to say that the Lubchenco charts do not represent the current Egyptian population of neonates, which leads to misclassification of small-for-gestational age and large-for-gestational age newborns. As such, it is highly recommended to utilize new national anthropometric charts when assessment of full term Egyptian newborns is considered.
\end{abstract}

Keywords Neonatal anthropometry; percentiles; Egypt; Newborn birth weight; newborn length; newborn head circumference; newborn skin fold thickness

Corresponding author: Rania Mohamed Abdou E-mail: raniaabdou@med.asu.edu.eg

\section{Introduction}

The most popularly used neonatal anthropometric charts are based on the distribution of measurements, mainly birthweight of neonates at different gestational ages. ${ }^{1}$ Many authors have postulated that the assessment of body proportions may be more useful than relying on a single measurement for age alone for assessment of the newborn nutritional status. ${ }^{2}$ In clinical practice, a neonate is classified as small for gestational age (GA), appropriate for GA, or large for GA on the basis of threshold values derived from the distribution of a given anthropometric trait (e.g. birth weight) in a population of neonates in the form of a standard, or more often a reference. ${ }^{1}$ A standard is based on highly restrictive criteria aimed at excluding all neonates that might have been exposed to potential risk factor that can undermine fetal growth, thus denoting "how growth should be." In the absence of these exclusion criteria, a chart is considered a reference, denoting "how growth actually is." Presently, the majority of used neonatal charts are essentially references. ${ }^{1}$ The heterogeneity of methods used to 
analyze these charts, yields a wide variation in the threshold values, which do not necessarily reflect substantial variations across different population groups. It is currently widely agreed that each country should formulate and/or update its own national charts. ${ }^{2}$ Centile charts of birth weight for gestational age represent an indispensable tool for many epidemiological studies, and they also offer valuable information to clinicians, especially in determination of newborns who may be at higher risk for neonatal or postnatal morbidit. ${ }^{4}$ Accordingly, it is pivotal to use charts that are representative of the population to which they are applied. ${ }^{1}$

Accurate measurement of body length at birth is extremely helpful in the diagnosis of abnormal growth, later on during routine follow-up, in the prognosis of final height, and in the consideration of possible therapeutic interventions. ${ }^{3}$ In nearly all term births, lighter and smaller infants tend to have more morbidity and worse survival expectancy, when compared to heavier infants. Nevertheless, what is striking is that infants with greater subcutaneous fat had less morbidity and better survival rate, mainly due to the fact that the neonate uses subcutaneous fat both as an energy source and as an insulating agent to shield himself/herself against heat loss. ${ }^{4}$ Finally, the classification of new-born infants, by plotting their anthropometric parameters as birth weight, length, head circumference and skin fold thickness, against their gestational age, on standard growth charts are crucial in reflecting intrauterine growth and establishing a baseline to follow-up the nutritional progress of the infant. ${ }^{2}$

We aimed to formulate anthropometric percentile values for Egyptian newborns and to compare these values with the currently used international charts.

\section{Method}

The research was carried out in the form of a cross-sectional study for 3 years. The studied sample comprised 6892 term newborn, of which 112 subjects were excluded due to considerable discrepancy existing between the gestational age calculated via the date of the last menstrual period, and the modified Ballard score. ${ }^{5}$ All subjects were delivered over a period of three years from May 2012 to May 2015 from 3 different hospitals, Cairo, Egypt. Ain shams university maternity hospital which represents a tertiary health facility to which cases are referred from all over the country, and two private hospitals. Hence, the sample is representative of different socioeconomic standard

The study was approved by the pediatric hospital research and ethical committee Ain Shams University. An informed consent was obtained from all the caregivers to include the anthropometric measures of their newborn in a study.

We included single births full term neonates $\geq 37$ weeks) born to Egyptian parents

We excluded from the study preterm neonates $\quad(<37$ weeks $)$,newborns with congenital anomalies, maternal disorders or risk factors that might have affected fetal growth including diabetes mellitus, preeclampsia, hypertension, cardiac diseases, smoking, alcoholism and drug abuse.

For all included subjects, the following was done: (1) History taking including determination of the gestational age at delivery on basis of last menstrual period (LMP) calculation, determination of significant incidents during the antenatal period including drug administration, hormonal therapy, smoking and symptoms suggestive of congenital infections. This was essential to exclude subjects with factors that can affect fetal growth and birth weight. (2) Clinical examination of the newborn including assessment of the gestational age using Ballard's modified scoring system $^{5}$ (3) Anthropometric measurements within 24 hours after delivery: Birth weight: was measured via 
means of an accurate electronic scale, by the neonatology resident, in kilograms. A German, Seca 334, mobile electronic baby scale was used. The scale was placed on a flat, horizontal surface and turned on. When the scale's monitor displayed 0.00 $\mathrm{Kg}$, the newborn was placed naked on the scale to be weighed, soon after delivery and before administration of the first fed. Length: was recorded using a Harpenden neonatometer. The neonatology resident, or the author, and a nurse worked together to measure the length of every subject, with the neonatology resident positioning the head appropriately in Frankfort's vertical plane and the nurse fully extending the newborn's lower limbs. Length was measured with the back straightened, the head board placed against the head and the movable foot board pressed gently against the feet balls. Head circumference: The infant's head circumference was measured by the neonatology resident, or the author, using a non-stretchable, plasticized 0.25 inch wide measuring tape. An insertion type tape was used, i.e. one end of the tape inserts into the other, to aid in providing a more precise "view" of the circumference measurement. Head circumference, or occipitofrontal circumference, is measured over the occiput, i.e. the most prominent part of the back of the head, and just above the supraorbital ridges, i.e. the eyebrows. In other words, the aim was to measure the largest possible head circumference. Skin Fold Thickness: Measured by the neonatology resident, or the author, in millimeters via means of a manual Harpenden calipers. We measured the skin fold thickness over the triceps at the midpoint of the left arm. The midpoint of the left arm was identified by measuring It is unarguable that there is marked genetic differences among various races the distance between the acromion and olecranon processes, with the neonate in dorsal decubitus, the arm lying laterally to the trunk, and the elbow flexed at a 90 degree angle. A mark was made at the located point and then the skin was pinched firmly between the index finger and the thumb, pulling it slightly away from the underlying tissues, and applying the calipers for taking the measurement of the skin fold thickness. Three consecutive measurements were taken for each newborn from 3 areas; the triceps, biceps and mid-thigh, and the mean value was considered after rounding it to the nearest millimeter. 5- Gestational Age: was estimated via last menstrual period calculations, early ultrasonography and the new Ballard score.

Data coding and Statistical Analysis: Data coding was done using Microsoft's Excel and IBM's SPSS statistical analysis software package 15.0 was used on Windows 8 OS. Statistical analyzes were performed to estimate the arithmetic mean, range, standard deviation (s), percentile values and the p-value. Significance of statistical difference of a given variable was considered for $p$-values equal to or less than 5. All variables were com-pared using the t-test. Charts and curves were plotted using Microsoft's Excel 2003.

\section{Results}

The study was undertaken on 6892 Egyptian full term newborns. Our exclusion criteria led to omitting 112 subjects, so the study eventually involved 6780 subjects. 3451 of whom were males and 3329 were females.

Results are illustrated in table 1 to 4 .

\section{Discussion}

when growth and body composition are to be considered. Retrospective birth weight 
Table (1): The variation of the anthropometric measures between term male and term female newborn

\begin{tabular}{|l|l|r|r|r|r|}
\hline & Sex & No. & Mean & SD & p \\
\hline GA & Male & 3451 & 38.53 & 1.08 & 0.5 \\
(in weeks) & Female & 3329 & 38.49 & 1.12 & \\
\hline Weight & Male & 3451 & 3.23 & 0.53 & 0 \\
(in kg) & Female & 3329 & 3.06 & 0.48 & \\
\hline Length & Male & 3451 & 50.28 & 2.54 & 0 \\
(in cm) & Female & 3329 & 49.2 & 2.56 & \\
\hline HC & Male & 3451 & 34.95 & 1.36 & 0 \\
(in cm) & Female & 3329 & 34.19 & 1.37 & \\
\hline SFT & Male & 3451 & 4.22 & 1.01 & 0.002 \\
(in mm) & Female & 3329 & 3.95 & 0.98 & \\
\hline
\end{tabular}

GA: gestational age, HC: head circumference,

SFT: skin fold thickness, $N$ : number, SD: standard deviation, GA: gestational age by LMP, $t^{*}=$ student test.

Table (2): Head Circumference and Skin Fold Thickness in term male and term female newborn

\begin{tabular}{|c|c|c|c|c|c|c|c|c|c|c|c|c|c|c|c|c|c|c|c|}
\hline & \multicolumn{10}{|c|}{ Head circumference in cm } & \multicolumn{9}{|c|}{ Skin fold thickness in mm } \\
\hline \multicolumn{2}{|c|}{$\begin{array}{l}\text { GA } \\
\text { (W) }\end{array}$} & $97^{\text {th }}$ & $95^{\text {th }}$ & $90^{\text {th }}$ & $75^{\text {th }}$ & $50^{\text {th }}$ & $25^{\text {th }}$ & $10^{\text {th }}$ & $5^{\text {th }}$ & $3^{\text {rd }}$ & $97^{\text {th }}$ & $95^{\text {th }}$ & $90^{\text {th }}$ & $75^{\text {th }}$ & $5^{0^{\text {th }}}$ & $25^{\text {th }}$ & $10^{\text {th }}$ & $5^{\text {th }}$ & $3^{\text {rd }}$ \\
\hline \multirow{4}{*}{ 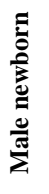 } & 37 & 36.8 & 36.2 & 35.6 & 34.4 & 34.1 & 33.4 & 33.1 & 32.6 & 32 & 6.8 & 6.3 & 5.5 & 4.2 & 3.8 & 3.5 & 3 & 2.8 & 2.8 \\
\hline & 38 & 37.4 & 37 & 36.2 & 35.5 & 35 & 34 & 33.5 & 33.2 & 32.5 & 5.7 & 5.2 & 5 & 4.5 & 4 & 3.5 & 3 & 2.7 & 2.5 \\
\hline & 39 & 37.7 & 37.5 & 36.5 & 36 & 35.5 & 34.5 & 34 & 33.5 & 33 & 7 & 6.3 & 5.5 & 4.9 & 4 & 3.6 & 3,3 & 2.6 & 2.4 \\
\hline & 40 & 38 & 37.5 & 37 & 36.5 & 35.8 & 35 & 34.5 & 34 & 33.5 & 6.2 & 6.2 & 6 & 5.2 & 4.4 & 3.8 & 3 & 2.8 & 2.8 \\
\hline \multirow{4}{*}{ 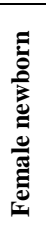 } & 37 & 36.2 & 36 & 35.5 & 34.5 & 33.75 & 33 & 32 & 31.5 & 31.4 & 6.3 & 5.9 & 5.5 & 4.4 & 3.8 & 3 & 2.8 & 2.6 & 2.4 \\
\hline & 38 & 36.5 & 36.3 & 36 & 35 & 34 & 33.3 & 32.5 & 32 & 31.4 & 5.7 & 5.2 & 5 & 4.2 & 3.9 & 3.2 & 2.9 & 2.6 & 2.5 \\
\hline & 39 & 37.3 & 36.8 & 36.5 & 35.2 & 34.5 & 34 & 33 & 32.4 & 32 & 5.8 & 5.2 & 5 & 4.4 & 4 & 3.2 & 2.9 & 2.6 & 2.5 \\
\hline & 40 & 37.4 & 37 & 36.5 & 35.7 & 35 & 34.5 & 34 & 33.2 & 32.6 & 6 & 5.6 & 5.2 & 4.8 & 4.4 & 3.8 & 3.2 & 2.9 & 2.5 \\
\hline
\end{tabular}

Table (3): Birth Weight and Length in term male and term female newborn

\begin{tabular}{|c|c|c|c|c|c|c|c|c|c|c|c|c|c|c|c|c|c|c|c|}
\hline & \multicolumn{10}{|c|}{ Birth weight in $\mathrm{Kg}$} & \multicolumn{9}{|c|}{ Birth length in cm } \\
\hline \multicolumn{2}{|c|}{$\begin{array}{l}\text { GA } \\
\text { (W) }\end{array}$} & $97^{\text {th }}$ & $95^{\text {th }}$ & $90^{\text {th }}$ & $75^{\mathrm{th}}$ & $50^{\text {th }}$ & $25^{\text {th }}$ & $10^{\text {th }}$ & $5^{\text {th }}$ & $3^{\text {rd }}$ & $97^{t^{\text {th }}}$ & $95^{\text {th }}$ & $90^{\text {th }}$ & $75^{\text {th }}$ & $50^{\text {th }}$ & $25^{\text {th }}$ & $10^{\text {th }}$ & $5^{\text {th }}$ & $3^{\text {rd }}$ \\
\hline \multirow{4}{*}{ 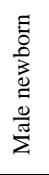 } & 37 & 3.93 & 3.7 & 3.5 & 3.1 & 2.9 & 2.6 & 2.5 & 2.3 & 2 & 53 & 51.5 & 51 & 50 & 48 & 47.5 & 47 & 46 & 45 \\
\hline & 38 & 4.2 & 4.1 & 3.8 & 3.4 & 3.1 & 3.1 & 2.7 & 2.6 & 2.4 & 55 & 53.7 & 52.5 & 51.7 & 50 & 48.5 & 47.2 & 46 & 46 \\
\hline & 39 & 4.3 & 4.2 & 4.2 & 3.8 & 3.3 & 3.1 & 2.8 & 2.7 & 2.6 & 54 & 54.1 & 53 & 52 & 51 & 49 & 47.5 & 47 & 46.2 \\
\hline & 40 & 4.4 & 4.3 & 4.2 & 3.9 & 3.6 & 3.3 & 2.9 & 2.7 & 2.5 & 56 & 55 & 54 & 53.5 & 52 & 50 & 48 & 47 & 46.6 \\
\hline \multirow{4}{*}{ 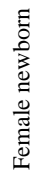 } & 37 & 3.75 & 3.69 & 3.5 & 3.2 & 2.8 & 2.5 & 2.2 & 2.1 & 2 & 52.6 & 52.3 & 52 & 49 & 48 & 46.6 & 45 & 44.1 & 44 \\
\hline & 38 & 3.82 & 3.72 & 3.6 & 3.3 & 3 & 2.75 & 2.5 & 2.2 & 2 & 53.5 & 53 & 52.4 & 50 & 48.5 & 47.2 & 45.6 & 44.8 & 44.5 \\
\hline & 39 & 3.95 & 3.87 & 3.7 & 3.5 & 3.2 & 2.87 & 2.55 & 2.41 & 2.3 & 54 & 53.5 & 52.5 & 50 & 49 & 48 & 47 & 46.1 & 46 \\
\hline & 40 & 4.32 & 4.2 & 3.9 & 3.6 & 3.3 & 3 & 2.7 & 2.5 & 2.5 & 54.5 & 54 & 53 & 52 & 50 & 49 & 48 & 46.2 & 46 \\
\hline
\end{tabular}

Throughout our study, the mean birth weight of full term male newborns at 37 , 38,39 and 40 weeks of gestation were higher than the mean birth weight of full term female newborns at same weeks of gestation. These results exhibited significant variance ( $\mathrm{p}$-value $<0.05)$. These results are in accordance with a South data highlights the pivotal role of geographic location as an environmental factor influencing fetal growth. As such, the most convenient way to precisely evaluate the growth status of a pediatric population is to formulate regional individualized growth charts specific for each population group.

This study was designed to establish anthropometric percentile values for Egyptian newborns and to compare these values with the currently used international charts. 
denotes that full term male newborns were also heavier than full term female newborns, so their results closely resembled ours. ${ }^{6}$

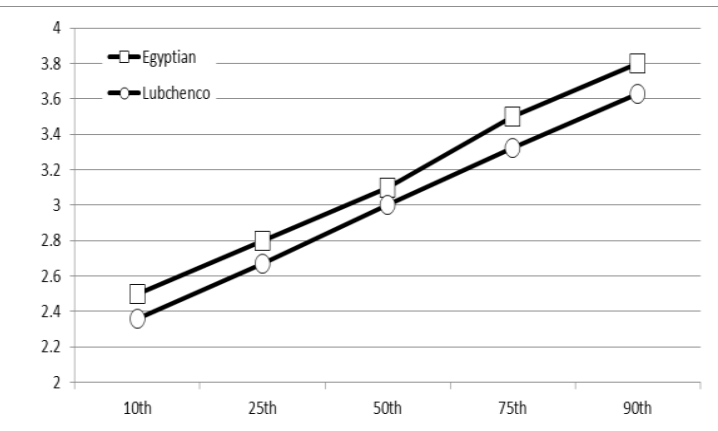

Figure (1): Comparison of our birth weight in $\mathrm{Kg}$ percentiles of full term neonates with data from Lubchenco charts

Our results were also much similar to those of a Chinese study, where the mean body weight of Chinese full term male newborns at 37, 38, 39 and 40 weeks of gestation, were $3.11 \mathrm{~kg}, 3.2 \mathrm{~kg}, 3.35 \mathrm{~kg}$ and $3.5 \mathrm{~kg}$ respectively, while the mean body weight of Chinese full term female newborns at 37, 38, 39 and 40 weeks of gestation, were $3.04 \mathrm{~kg}, 3.19 \mathrm{~kg}, 3.27 \mathrm{~kg}$ and $3.37 \mathrm{~kg}$ respectively, which also points to the conclusion that full term male newborns are heavier than full term female newborns. ${ }^{6}$ Oppositely, our results were different from those of a European study, where the body weight of European full term male newborns at 37, 38, 39 and 40 weeks of gestation were $3.33 \mathrm{~kg}, 3.35 \mathrm{~kg}$, $3.58 \mathrm{~kg}$ and $3.68 \mathrm{~kg}$ respectively, whereas the body weight of European full term female newborns were $3.05 \mathrm{~kg}, 3.29 \mathrm{~kg}$, $3.45 \mathrm{~kg}$ and $3.63 \mathrm{~kg}$ respectively. So, even though European full term males were still heavier than European full term females, both males and females within the European study were heavier than their Egyptian peers, as per the results of our study. ${ }^{7}$

These results may be attributed to better quality of antenatal care and higher socioeconomic status among the European population group, apart from maternal exhaustion, lower quality of antenatal care services, higher susceptibility to infection, faulty maternal dietary habits and exposure to passive smoking during pregnancy, which have all proven to contribute to the neonatal outcome in Egypt. ${ }^{7}$

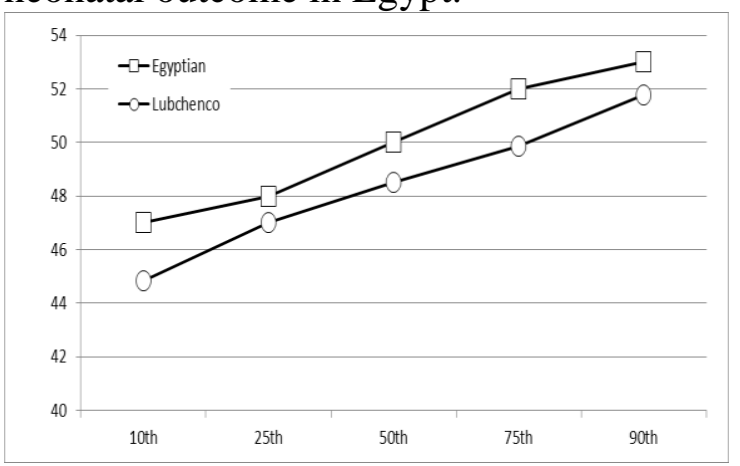

Figure (2): Comparison of our length in $\mathrm{cm}$ percentiles for Egyptian full term neonates with data derived from the Lubchenco chart.

When considering the length measurements of male and female full term newborns, full term males were significantly longer than full term females (p-value < 0.05). The results are in accordance with the afore-mentioned South Asian study, where the mean length of South Asian full term males at 37, 38, 39 and 40 weeks of gestation were 48.7 $\mathrm{cm}, 50.2 \mathrm{~cm}, 50.2 \mathrm{~cm}$ and $50.4 \mathrm{~cm}$ respectively, while the mean length of South Asian full term females were 48.2 $\mathrm{cm}, 48.8 \mathrm{~cm}, 49.5 \mathrm{~cm}$ and $50 \mathrm{~cm}$ respectively, which denotes that their full term males were also longer than their full term females peers, which resembles the results of our study. ${ }^{6}$ The results of our study are also compatible with those of a Chinese study, where the mean length of full term male newborns at 37, 38, 39 and 40 weeks of gestation were $48.3 \mathrm{~cm}, 48.4$ $\mathrm{cm}, 49.4 \mathrm{~cm}$ and $50 \mathrm{~cm}$ respectively, while the mean length of the full term female newborns at $37,38,39$ and 40 weeks of gestation were $47.6 \mathrm{~cm}, 48.2 \mathrm{~cm}, 48.7 \mathrm{~cm}$ and $49.2 \mathrm{~cm}$ respectively. As such, Chinese full term male newborns were longer than their female peers, but both were slightly shorter than their Egyptian 
peers, especially between the 39 th and $40^{\text {th }}$ weeks of gestation. ${ }^{6}$ The values of our results were also close to those of a European study, where the mean lengths of full term male newborns at 37, 38, 39 and 40 weeks of gestation were $49.4 \mathrm{~cm}, 49.4$ $\mathrm{cm}, 50.5 \mathrm{~cm}$ and $50.8 \mathrm{~m}$ respectively, while the mean lengths of full term female newborns at 37, 38, 39 and 40 weeks of gestation were $47.4 \mathrm{~cm}, 48.6 \mathrm{~cm}, 49.4 \mathrm{~cm}$ and $50.2 \mathrm{~cm}$ respectively, denoting that European full term male newborns are longer than their female peers and the European values are close to the values of our results. ${ }^{7}$ Variation in birth length may be attributed to genetic and racial differences among different population groups as they are main determinants of birth length. ${ }^{8}$

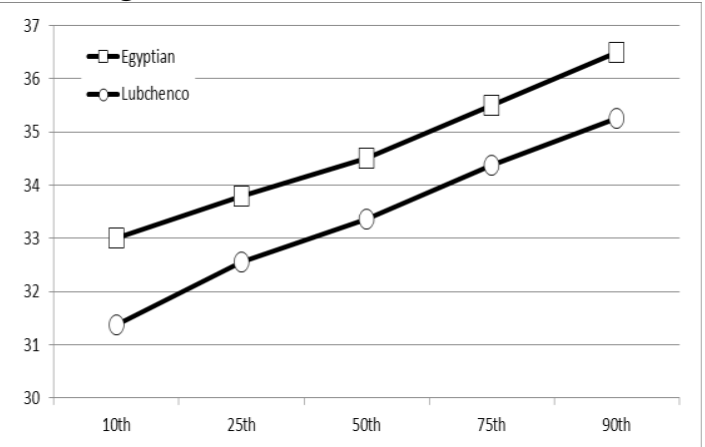

Figure (3) : Comparison of our head circumference in $\mathrm{cm}$ percentiles for full term neonates with data derived from the Lubchenco chart.

The mean head circumference of the full term male newborns in our study at 37,38 , 39 and 40 weeks of gestation larger head circumference than term females of same gestational age respectively. These results are in accordance with a South Asian study, where the mean head circumference of full term male newborns at 37, 38, 39 and 40 weeks of gestation were $34.6 \mathrm{~cm}$, $34.3 \mathrm{~cm}, \quad 34.6 \mathrm{~cm}$ and $35.2 \mathrm{~cm}$ respectively, while the mean head circumference of the full term females in the same study at $37,38,39$ and 40 weeks of gestation were $33 \mathrm{~cm}, 33.7 \mathrm{~cm}, 34.2 \mathrm{~cm}$ and $34.7 \mathrm{~cm}$ respectively, which denotes that South Asian term males have bigger head circumference than their female peers, and collectively, the values of the South Asian study highly resemble the values of our study, except that Egyptian term males, in our study, had significantly bigger head circumference than the South Asian full term males between the 39th and 40th weeks of gestation. ${ }^{9}$ Also, our results go hand in hand with the results of a Chinese study where the mean head circumference of Chinese full term males at $37,38,39$ and 40 weeks of gestation were $33.9 \mathrm{~cm}, 34.3 \mathrm{~cm}, 34.8 \mathrm{~cm}$ and 34.9 $\mathrm{cm}$ respectively, whereas the mean head circumference of full term females in the same study at $37,38,39$ and 40 weeks of gestation were $33.4 \mathrm{~cm}, 33.8 \mathrm{~cm}, 34.1 \mathrm{~cm}$ and $34.3 \mathrm{~cm}$ respectively, which means that Chinese full term male newborns have bigger head circumference than their females counterparts, yet Egyptian newborns have slightly bigger head circumference than their Chinese peers. ${ }^{9}$ The results of our study are also compliant with the results of a European study, where the mean head circumference of European full term males at 37, 38, 39 and 40 weeks of gestation were $34.5 \mathrm{~cm}, 34.7 \mathrm{~cm}, 35.2$ $\mathrm{cm}$ and $35.4 \mathrm{~cm}$ respectively, while the mean head circumference of European full term females at 37, 38, 39 and 40 weeks of gestation were $33.8 \mathrm{~cm}, 34 \mathrm{~cm}, 34.3 \mathrm{~cm}$ and $34.7 \mathrm{~cm}$ respectively, which means that their full term males had bigger head circumference than their female peers and the values closely resemble those of Egyptian full term newborns. ${ }^{10}$ Maternal age, maternal preconception weight, smoking, parity, frequency of antenatal care visits and maternal level of education are major determinants of the body weight, length and head circumference of full term newborns. ${ }^{10}$ These factors need to be thoroughly investigated to determine their direct effects on neonatal anthropometry amongst our population.

In our study the mean skin fold thickness results exhibited significant variance (pvalue $<0.05$ ) when comparing the skin 
fold thickness of both full term male and female newborns, as full term males had larger skin fold thicknesses than full term females. These results are not in accordance with the results of Rodrýguezet al., 2005 where the mean skin fold thickness of full term females was greater than that of full term males across both full and preterm age groups. ${ }^{11}$ These contradictory results of the two studies can be explained by variation in the technique of measurement of skin fold thickness, where Rodrýguez's team measured the skin fold thickness over four muscle sites; triceps, biceps, subscapular area and suprailiac area, whereas in our study, we measured the skin fold thickness at three sites; biceps, triceps and mid-thigh and the mean for all three measurements was calculated and used. The current findings of skin fold thick-ness need further assessment of the factors that influence the deposition of subcutaneous fat in both male and female full term newborns to help in the justification of the results of our study.

We compared our newly established birth weight, length and head circumference percentiles with the most commonly used percentiles of the Lubchenco charts. The mean birth weight of newborns in our studied population is $3.1 \mathrm{~kg}$, while it valued $3.03 \mathrm{~kg}$ on the Lubchenco chart. Our study's 10th, 50th and 90th body weight percentiles were above those of the Lubchenco percentiles at 37, 38, 39 and 40 weeks of gestation. These results are similar to the results of Davidson et al.'s work in 2008, where the mean birth weight of full term male newborns was $3.24 \mathrm{~kg}$ and that of full term females was $3.12 \mathrm{~kg}$ in Israel, which are also above the values of the Lubchenco charts. ${ }^{12}$

The mean length of a full term newborn, in our studied population, was $50 \mathrm{~cm}$, while on the Lubchenco charts, the mean length values $48.5 \mathrm{~cm}$. The 10th, 50th and 90th percentiles of the length of the full term newborns we studied were above those of the Lubchenco percentiles at 37, 38, 39 and 40 weeks of gestation.

The mean head circumference of a full term newborn among our studied population was $34.5 \mathrm{~cm}$, while it valued $33.3 \mathrm{~cm}$ on the Lubchenco charts. The $10^{\text {th }}$, $50^{\text {th }}$ and $90^{\text {th }}$ percentiles of the head circumference of our studied population were higher than those of the Lubchenco percentiles at 37, 38, 39 and 40 weeks of gestation. This data is in accordance with Irene et al.'s study in 2010 on newborns in the United States, as they found that smallfor-gestational age and large-forgestational age classifications, using the Lubchenco charts, differ significantly from the new charts for each gestational age group. ${ }^{13}$ Similarly, in Britton's study in 1993, in Arizona, birth weight, height and head circumference of full term male newborns were significantly higher than the results of previous studies, which denotes that interpretation using old values could be rather misleading. ${ }^{14}$ However, the results of our study were against those of Kalanda et al.'s work in 2005, where birth weight, height and head circumference of newborns in Malawi with gestational age between 35 and 41 weeks, were significantly lower at all percentile levels, when compared to newborns from developed countries. ${ }^{15}$ These results may be attributed to various genetic, geographical and environmental factors among different population groups; general improvements of the quality of health care services and changes in obstetric practices. Maternal age, maternal preconception weight, smoking history, parity, frequency of antenatal care visits and maternal level of education were all observed as essential factors in the determination of body weight, length and head circumference of full term newborns. All the aforementioned factors are well known to influence the anthropometric measurements of a newborn, which can vary from one population group to the other. Accordingly, population based 
intrauterine growth percentiles are indispensable to better assess each population group. ${ }^{10}$ It has been postulated that high altitude geographical locations can be associated with the delivery of small babies. ${ }^{16}$ Small-for-gestational age and Large-for-gestational age are commonly used to define high risk groups of newborns who would need extra attention in the NICU; Small-forgestational age newborns are at higher risk for adverse outcomes such as hypoglycemia, hypothermia and growth and neuro-developmental delays, while Large-for-gestational age newborns are at higher risk for development of early hypoglycemia and the metabolic syndrome later on in their lives. Using the old Lubchenco unisex charts leads to misclassification that can cause many small-for-gestational age newborns not receiving the care they need, as they are misclassified as appropriate-for-gestational age. Large-for-gestational age newborns can be overlooked because they are misclassified as appropriate-for-gestational age, and other newborns may be improperly prescribed extra NICU attention, mainly because they are classified as large-for-gestational age. This can lead to misdirection of NICU's resources and suboptimal outcomes of NICU admitted neonates. Further re-search is mandatory to correlate the new definitions of small-for-gestational age and large-for-gestational age neonates with short term and long term health outcomes. $^{13}$

\section{Conclusion}

The Lubchenco charts are not representative of the current Egyptian population. The new intrauterine growth charts formulated in this study, which were based on a large Egyptian sample, provide clinicians with an updated tool for growth assessment in Egyptian NICUs.

\section{Recommendations}

Further research is needed to update national charts for more gestational age groups and preterm neonates and across different regions and to better define small-for-gestational age and large-forgestational age groups in Egypt to identify high risk infants when short term and long term health outcomes are considered.

\section{References:}

1. Bertino E, Spada E, Occhi L, Coscia A, Giuliani F, Gagliardi L etal. Neonatal anthropometric charts: the Italian neonatal study compared with other European studies. J Pediatr Gastroenterol Nutr. 2010 Sep; 51(3):353-61.

2. Brock R, Falcao M., Leone C. Body mass index values for newborns according to gestational age. Nutr Hosp.2008; 23(5):487492.

3. Petah, Sackler. The Diagnostic and Prognostic Importance of Neonatal Length Measurements. A Name behind A Syndrome. Schneider Endocrinology and Diabetes Children's Medical Center of Israel. 2000; 2:84-85.

4. Copper RL, Goldenberg RL, Cliver SP, DuBard MB, Hoffman HJ, Davis RO. et al. Anthropometric Assessment of Body Size Differences of Full-Term Male and Female Infants. American College of Obstetrics and Gynecology. 1993; 81:161-4.

5. Ballard JL, Khoury JC, Wedig K, Wang L, Eilers-Walsman BL and Lipp R. New Ballard Score, expanded to include extremely premature infants. J Pediatrics; 1991; 119:417423.

6. Janssen PA, Thiessen P, Klein MC, Whitfield MF, MacNab YC, Cullis-Kuhl SC. Standards for the measurement of birth weight, length and head circumference at term in neonates of European, Chinese and South Asian ancestry. Open Medicine 2007; 1(2):e74-88.

7. Hassan NE, Shalaan AH, and El-Masry SA. Relationship between maternal characteristics and neonatal birth size in Egypt. EMHJ. 2011; $17: 4$.

8. Cohen P, Rogol AD, Deal CL. ISS Consensus Work-shop participants. Consensus statement on the diagnosis and treatment of children with idiopathic short stature: a 
summary of the Growth Hormone Research Society, the Lawson Wilkins Pediatric Endocrine Society, and the European Society for Pediatric Endocrinology Workshop. J Clin Endocrinol Metab. 2008; 93:4210-4217.

9. Wen SW, Kramer MS, Usher RH. Comparison of birth weight distributions between Chinese and Caucasian infants. Am J Epidemiol. 1995; 141(12):1177-1187.

10.Salihoglu O, Karatekin G, Uslu S, Can E, Baksu B, Nuhoglu A. New intrauterine growth percentiles: a hospital-based study in Istanbul, Turkey. JPMA. 2012; 62: 1070.

11.Rodríguez G, Samper MP, Olivares JL, Ventura P, Moreno LA, Pérez-González JM (2005): Skin fold measurements at birth: sex and anthropometric influence. Arch Dis. Child Fetal Neonatal.2005; 90: 273-275.

12.Davidson S, Sokolover N, Erlich A, Litwin A, Linder N, Lea Sirota L. new and improved Israeli reference of birth weight, birth length, and head circumference by gestational age: a hospital-based study Israeli Neonatal Anthropometry Reference Isr Med Assoc J. 2008;10 (2):130-134.

13. Olsen IE, Groveman SA, Lawson ML, Clark RH, Zemel BS. New Intrauterine Growth Curves Based on United States Data. Pediatrics. 2010; 125:2.

14.Britton JR. Weight, length, head and chest circumference at birth in Phoenix, Arizona. Journal of reproductive medicine, 1993, 38:215-22.

15.Kalanda BF, Van Buuren S, Verhoeff FH, and Brabin BJ. Anthropometry of Malawian live births between 35 and 41 weeks of gestation. Annals of Human Biology, September-October 2005; 32(5): 639-649.

16.Lubchenco LO and Battaglia FC. A practical classification of newborn infants by weight and gestational age. Journal of Pediatrics. 1967; 71(2):159-163. 